\title{
Scene Identification and Its Effect on Cloud Radiative Forcing in the Arctic
}

\author{
ZHANQING LI AND H. G. LEIGHTON
}

Department of Meteorology, McGill University, Montreal, Quebec, Canada

\begin{abstract}
Measurements of cloud radiative forcing in polar regions are less reliable than at lower latitudes because of the difficulty in distinguishing between clouds and ice- or snow-covered surfaces. Scene identification can, however, be improved by using multispectral narrow-band radiances. Comparisons were made between scenes identified by the Earth Radiation Budget Experiment (ERBE) algorithm and those deduced from Advanced Very High Resolution Radiometer (AVHRR) radiances in the Arctic for 4 days in July 1985. It was found that they differ significantly from each other both in geotype and in cloud cover. For instance, regions of clear fractional sea ice according to the AVHRR analysis are assigned as being cloudy over open ocean by the ERBE analysis owing to incorrect specification of the sea ice extent. Zonal averages over $2.5^{\circ}$ wide bands, of fluxes over clear and cloudy regions and hence also cloud forcing, are determined over the Arctic using radiances measured by the AVHRR on NOAA 9 to identify the nature of the scene and the ERBE radiometer to provide broadband radiances. Results are compared with fluxes and cloud forcing determined solely from ERBE radiometer data. Over the southern portion of the domain, where fractional sea ice was prevalent, the ERBE-based values of net cloud forcing were as much as $50 \mathrm{~W} \mathrm{~m}^{-2}$ smaller than values determined when the scene identification was based on AVHRR measurements. At higher latitudes the ERBE-estimated cloud forcing was larger than that from the AVHRR, and the magnitude of the difference was smaller.
\end{abstract}

\section{INTRODUCTION}

Understanding the influence of clouds on the Earth's radiation budget is essential to understanding the Earth's climate. Clouds influence the radiative heating of an atmospheric column by decreasing the loss of longwave radiation to space and by increasing the reflectivity of the column to shortwave radiation. The difference in the radiative heating of a column of cloudy air and a column of clear air is referred to as cloud radiative forcing. Correctly obtaining the values of cloud forcing is a major challenge to climate modelers, since the computed values are sensitive to the treatment of the influence of clouds on solar and terrestrial radiation. While theoretical studies based on the results of simulations with global climate models have suggested some general features of the cloud forcing distribution [Charlock and Ramanathan, 1985; Hartmann et al., 1986; Cess and Potter, 1987], they need verification by observational results, as has been done recently by Kiehl and Ramanathan [1990].

Cloud forcing depends not only on the cloud properties such as cloud type, cloud amount etc. but also on the clear-sky surface properties. One of the critical factors in observational cloud-forcing studies is the determination of whether a measurement corresponds to clear or cloudy skies. Identification of the nature of the scene is also important in converting the measured radiance to exitance. With the use of a scanning radiometer that measures radiance in one direction over a small viewing area, more detailed features of the spatial variation of the radiation budget can be revealed than those derived from measurements made by wide-angle nonscanning radiometers. Detailed

\section{Copyright 1991 by the American Geophysical Union.}

Paper number 91JD00529.

0148-0227/91/91JD-00529\$05.00 knowledge of the nature of the scene will allow the use of an appropriate bidirectional function or angular dependence model (ADM) to account for the anisotropy of the reflected shortwave or emitted longwave radiation at the top of the atmosphere. The shortwave ADM is generally a scene-dependent function of the geometric parameters, namely, solar zenith angle, viewing zenith angle and relative azimuth angle. The nature of the scene includes two aspects: geographic surface type (ocean, land, snow, or ice, etc.) and cloud conditions (cloud cover, cloud optical thickness, and cloud three-dimensional geometry). Scene identification is thus the first important step toward the determination of the influence of clouds on the radiation budget.

The Earth Radiation Budget Experiment (ERBE) with its broadband $(0.2-5.0 \mu \mathrm{m}$ and $5.0-50 \mu \mathrm{m})$ scanning radiometers aboard NOAA polar-orbiting satellites and the Earth Radiation Budget Satellite (ERBS), is providing a comprehensive data set to address observationally the problem of cloud forcing. Preliminary results from ERBE have provided a much better picture of the effect of clouds on the atmosphereearth system than was previously available [Ramanathan et al., 1989]. However, in many of the studies that used the ERBE data it was noted that considerable uncertainties exist in the measurements of cloud forcing over the Arctic or Antarctic regions and even the sign of the cloud forcing could be wrong [Ramanathan et al., 1989]. The main reason for this is that distinguishing between clear and cloudy scenes only on the basis of the broadband shortwave and longwave measurements over the bright ice- and snow-covered region is unreliable. Although polar cloud forcing contributes very little to the global mean cloud forcing owing to the relatively small area of the polar regions, it does play an important role in the formation of the Arctic climate. Moreover, polar climate change is of special importance in the diagnosis of the Earth's climate change, since models predict a relatively large response in the polar regions to increased concentrations of greenhouse gases.

Measurements of multichannel narrowband radiances from 
the Advanced Very High Resolution Radiometer (AVHRR) provide alternative methods of scene identification that are particularly useful at high latitudes [Ebert, 1989; Key and Barry, 1989; Key, 1990; N. Sakellariou, H.G. Leighton, and Z. Li, Identification of clear and cloudy pixels at high latitudes from AVHRR radiances, submitted to the International Journal of Remote Sensing, 1990]. Simultaneous and collocated observations made by the ERBE radiometers and the AVHRR aboard the same spacecraft, NOAA 9, allow insight into the reliability of the cloud forcing derived exclusively from the ERBE data through comparisons of the cloud forcing derived from ERBE radiance measurements with AVHRR-based scene identification.

Section 2 illustrates the problems encountered by the ERBE scene identification algorithm in the polar regions in summer and the potential of the multichannel AVHRR data. A new scene identification algorithm based on AVHRR data is formulated in section 3. Section 4 compares the ERBE scenes and AVHRR scenes in two aspects, geotype and cloud condition. The effect of scene misidentification on Arctic cloud forcing is investigated using the data from four days in July 1985 in section 5. Concluding remarks are made in section 6.

\section{SCENE IDENTIFICATION IN THE ARCTIC}

\subsection{Scene Identification Based on Broadband Measurements}

In one of the first attempts to correct for the anisotropic character of the reflected radiation, the Nimbus 3 broadband data were classified as viewing either ocean, land/cloud, or snow [Raschke et al., 1973]. More recently, on the basis of much more complete data measured from the Nimbus 7 Earth Radiation Budget (ERB) biaxial radiometer scanner, Taylor and Stowe [1984] developed a new set of ADMs for a wide range of scene types, including clear ocean, land, snow, ice, and overcast, with four cloud altitudes. An ADM for partly cloudy conditions was, however, not established. The ADM for partly cloudy conditions is not a simple linear combination of those for clear and overcast skies weighted by cloud amount, since directional reflectance patterns are strong functions of cloud geometry [Davies, 1984]. For the Earth Radiation Budget Experiment, ADMs were deduced primarily from the Nimbus 7 and GOES data for selected combinations of four categories of cloud cover and surfaces of land, ocean, desert, snow/ice, and a combination of land and ocean [Suttles et al., 1988, 1989].

In the ERBE scene identification algorithm, geographic type (geotype) is determined by a static process and is simply dependent on the navigation of the measurement area and the predetermined atlas of geotype. Cloud conditions are, however, identified by a dynamic procedure known as maximum likelihood estimation (MLE) [Smith et al., 1986]. The application of MLE in the ERBE algorithm is similar to the employment of a threshold method in the sense that clear scenes are assumed to be dark and warm, while cloudy skies are bright and cold. MLE, however, takes into account the variance within the same scene associated with changes in cloud height, cloud type, and atmospheric variables, as well as surface properties. Such variation is accounted for by statistical distributions characterized by the means and variances of the shortwave and longwave measurements, as well as their correlations. On the basis of these distributions, the shortwave-longwave plane is partitioned into regions of the most probable scene type for a particular pair of measured radiances. Simulation studies made by Wielicki and
Green [1989] showed that the MLE substantially improves cloud detection over the clear/cloud threshold used in the inversion of Nimbus 3 and Nimbus 7 ERB scanner data. It was, however, pointed out that the MLE-derived cloud cover should be interpreted with caution, since it best approximates the true cloud cover for "average" cloud heights and optical depths. This is because the a priori statistical data used by the MLE is an average of all observed cloud heights and optical depths. A consequence of this is that the MLE likely underestimates lowaltitude clouds because of the small contrast between the clouds and surface. In a comprehensive evaluation of the ERBE method, Diekmann and Smith [1989] found that large cloud amounts of thin, low clouds occurring over ocean were underestimated by the ERBE scene identification method when compared to AVHRR results.

In the Arctic, in addition to the small reflectivity contrast between cloud and surface due to the presence of snow and ice, the thermal contrast is also quite small owing to the frequent occurrence of temperature inversions or isothermal profiles. Therefore methods based on broadband radiance measurements such as MLE often may not correctly identify clouds. Even more importantly, geotype should not be treated as a static process in the polar summer melt season owing to the considerable temporal variability of the sea ice [Grenfell and Maykut, 1977; Comiso and Zwally, 1984].

The location of the ice/snow boundary prescribed for use in the ERBE scene identification algorithm may differ markedly from the observed boundary, as shown in Figure 1. Figure 1 shows the observed free-ice edge and the solid-ice boundary in the Arctic for the week of July 9, 1985, as given on the ice map for this period produced by the U.S. Navy/NOAA Joint Ice Center. Also drawn in Figure 1 is the prescribed ERBE ice/snow boundary, which is to the north of the observed solid-ice boundary over much of the region.

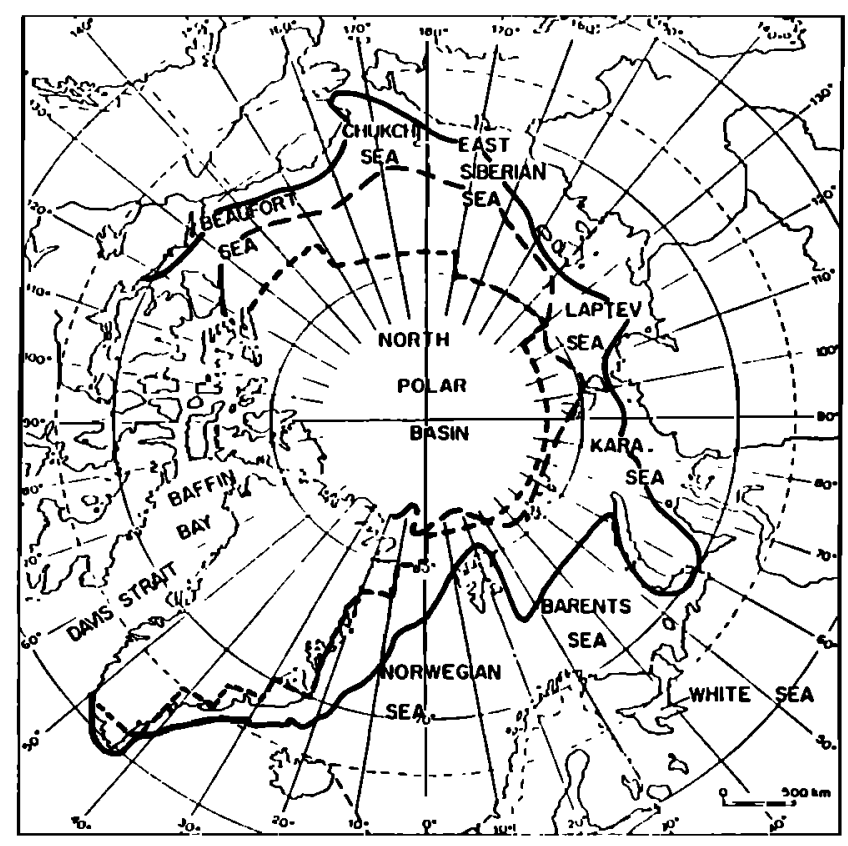

Fig. 1. Map showing ice boundaries in the Arctic. The solid curve is the ice-free boundary, and the long-dashed curve denotes the solid-ice boundary, both extracted from the sea-ice map for the week of July 9 , 1985, produced by the U.S. Navy/NOAA Joint Ice Center. The shortdashed curve shows the ice/snow specified by ERBE for July 10, 1985. 


\subsection{Potential of the AVHRR Data in Scene Identification}

The AVHRR radiometer is a multichannel detector sensitive to the following wavelength ranges: $0.58-0.68 \mu \mathrm{m}, 0.72-1.10$ $\mu \mathrm{m}, 3.55-3.93 \mu \mathrm{m}, 10.3-11.3 \mu \mathrm{m}$, and 11.5-12.5 $\mu \mathrm{m}$, designated as channels 1 - 5 , respectively. Reflectivities in channels 1 and 2 , denoted by $R_{1}$ and $R_{2}$, and brightness temperature in channels 4 and 5 are derived by applying the calibrations given by Lauritson et al. [1979] and Kidwell [1985]. The radiances in channel 3 include both the reflected solar radiation and emitted thermal radiation. The reflectivity in channel 3 is estimated by subtracting the filtered thermal radiance that would be emitted between 3.55 and $3.93 \mu \mathrm{m}$ from a blackbody radiating at the brightness temperature determined in channel 4.

While the variation of reflectivity with wavelength presents a variety of complicated relationships depending on the specific surface type [Bowker et al., 1985], some common features are well defined for four general scenes, namely, water, vegetated land, ice/snow, and cloud.

Water surfaces are weak reflectors and the spectral characteristics observed above the Earth are significantly modified by Rayleigh scattering resulting in a reflectivity in channel 2 that is smaller than in channel 1 . Over vegetated land the reflectivity is considerably larger at near-infrared wavelengths than at visible wavelengths. The denser the vegetation, the greater is the ratio of the reflectivities. By contrast, snow and ice are characterized by high reflectivity at visible wavelengths, with the reflectivity decreasing considerably toward the infrared [Grenfell and Perovich, 1984]. The reflectance of thick clouds decreases slightly from visible to near-infrared wavelengths, as calculated theoretically by Welch et al. [1980] and observed by Twomey and Cocks [1982]. Typical values of the ratio of reflectance in channel 2 to that in channel 1 are 0.5 for water, 1.6 for land (but with large variability), and close to unity for clouds [Saunders and Kriebel, 1988]. Snow and ice have a ratio less than unity but not always well separated from clouds. A large variety of investigations have shown the particular usefulness of radiance in channel 3 in the discrimination between clouds and highly reflective snow or ice surfaces [Kidder and $W u, 1984$; Raschke. 1987; Yamanouchi et al., 1987; Allen et al., 1990;
Harrison and Lucas, 1989; Gesell, 1989]. In this spectral region water clouds show a much higher reflectance for solar radiation, yet their emittance for terrestrial radiation is lower than in channels 4 and 5 [Raschke, 1988]. Ice clouds are more difficult to detect unless they are situated so high that they are readily differentiated from the surface by one of the thermal channels.

Ruff and Gruber [1983] took advantage of these multispectral data to tentatively identify clouds and surface types. Eighteen surface and cloud categories were differentiated by Ebert [1989] employing a pattern recognition algorithm for each of $2.5^{\circ} \times 2.5^{\circ}$ region. Sakellariou et al. (submitted manuscript, 1990) classify each pixel as belonging to one of four scene types: water, land, ice or snow, or cloud, based on radiances measured in all of the five channels. Figure 2 shows an example of cloud images identified by their method based on AVHRR measurements (Figure $2 a$ ), and by the ERBE algorithm (Figure $2 b$ ). The data are from pass 11 on July 10, 1985, over the Beaufort and Chukchi Seas. A comparison of the two images shows a considerable difference in the cloud distribution pattern. In particular, regions identified from the AVHRR data as being snow/ice surfaces under clear skies are classified as being overcast or mostly cloudy from the ERBE data. The synoptic map for this time lends much more support to the AVHRR results, as the clear area in Figure $2 a$ is under a high-pressure system, while the cloudy region is influenced by strong lowpressure circulation. The differences shown in this example are typical, and there is little doubt that cloud detection based on the AVHRR data is much more reliable than that based on ERBE data because of the multispectral information and higher resolution.

\section{DEVELOPMENT OF AVHRR SCENE IDENTIFICATION ALGORITHM}

In view of the limitations of the ERBE scene identification algorithm at high latitudes, a new method of classifying the scene type of ERBE pixels is required. The basis of the approach is to use AVHRR data that is matched geographically to the ERBE field of view (FOV) and to use the Sakellariou method to identify the nature of the AVHRR pixels.

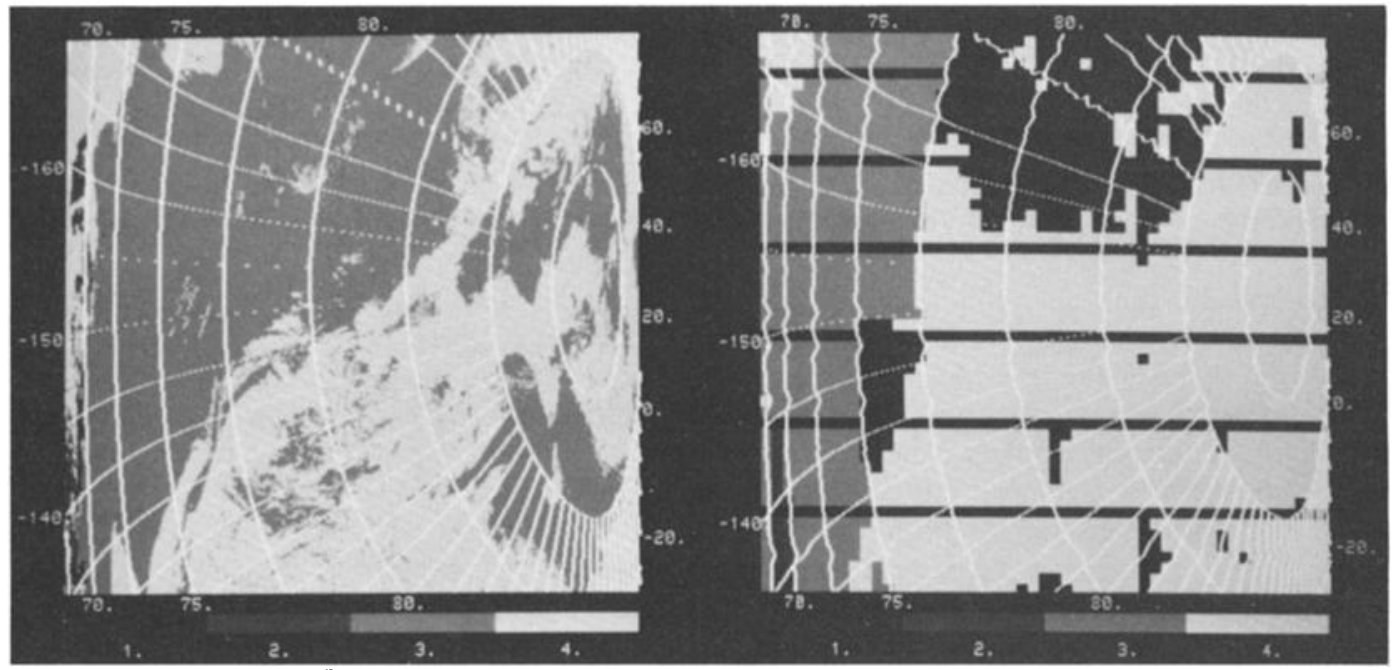

Fig. 2. (a) Scene types identified from AVHRR data from pass 11 on July 10, 1985, of NOAA 9. Shades 1-3 represent clear ocean, land, and fractional and solid ice, respectively, and shade 4 represents cloud. (b) Cloud classes identified by ERBE from the same pass as Figure $2 a$. Shades 1-4 represent clear, partly cloudy, mostly cloudy, and overcast skies, respectively. The numbers appearing on the top and the bottom of the image are latitudes, while those on the left and right edges are longitudes with negative values denoting the western hemisphere. 
In this method AVHRR scenes are divided into arrays of 34 x 34 global area coverage (GAC) pixels. A preliminary analysis of the scene types that are present is made on the basis of the reflectivities in channels 1,2 and 3 , and the brightness temperature in channel 4 . This analysis may and often will reveal that not all categories of pixels are present in a particular $34 \times 34$ pixel scene. Depending on which scene types are found to be present, the initial criteria are modified, and a threshold in the difference in the brightness temperatures $T_{4}-T_{5}$ is applied. The method was validated by comparisons with independent manual analyses of visual and infrared images, synoptic analyses, and a quite different automatic analysis procedure developed by Ebert [1989].

The data used are from NOAA 9, which carries both the AVHRR and the ERBE scanning radiometer. Both of the radiometers scan the Earth in a crosstrack direction, which allows simultaneous and coincident measurements. The nominal resolutions of the ERBE radiometer and the AVHRR are 40 $\mathrm{km}$ and $1.1 \mathrm{~km}$, respectively. However the AVHRR data are used in the global area coverage form, with a reduced resolution of $4 \mathrm{~km}$. To identify the AVHRR pixels that fall within a particular ERBE field of view, the AVHRR pixel that is closest to the center of the ERBE FOV is identified. The separation between the center of this AVHRR pixel and the center of the ERBE pixel is generally less than $2 \mathrm{~km}$; if it is greater than $5 \mathrm{~km}$ the ERBE data is flagged and not used. The array of $8 \times 8$ AVHRR pixels centered on the closest pixel is assumed to correspond to the ERBE pixel.

Since polar clouds are often thin, it is useful to extend Sakellariou's method (which only provides the surface type for clear pixels), to deduce, where possible, the nature of the surface under thin cloud. Cloudy pixels, for example, with $R_{2}-R_{1}$ substantially greater than zero are most likely thin clouds over land, whereas cloudy pixels with $R_{2}-R_{1}$ much smaller than zero very probably have surfaces of ice or snow. Thin cloud over ocean should have small values of $R_{2}-R_{1}$ and moderately small $R_{2}$.

To gain an impression of the potential of the reflectances in channels 1 and 2 to discriminate between surface types under thin clouds, Figure $3 a$ shows a plot of $R_{2}-R_{1}$ against $R_{2}$ for pixels in a scene of 150 by $2500 \mathrm{~km}$ ( $34 \times 408$ pixels) extending across the satellite track from northeast to southwest and crossing the Siberian coast near the southwestern extremity of the scene. The northern portion of the region contains solid ice, a portion of which was covered by cloud. There is a stretch of open water off the coast and another area of cloud over the land and coastal region. Pixels identified by Sakellariou's algorithm as being clear ice/snow, clear ocean, and clear land are shown separately in Figures $3 b-3 d$, respectively. The ice-covered pixels lie along a line that can be interpreted as being due to varying fractions of ice and ocean, the ends of the line representing open water and solid ice. The land pixels also lie along a well-defined line, which can be accounted for by varying amounts of vegetation and water surface fraction in the coastal pixels [Sakellariou and Leighton, 1988]. Pixels which are shown in Figure $3 a$ but not Figures $3 b-3 d$ are cloudy. These pixels fall into three groups. The line of pixels extending from the cluster of ice-covered pixels evidently consists of thin clouds over ice. This identification is confirmed by the geographic location of these pixels in the northeastern portion of the scene in the region of solid ice. The pixels with positive values of $R_{2}-R_{1}$ that trail away from the line of clear land-covered pixels are thin cloud over land. Again this identification is reinforced by the geographic location of the pixels. The middle group of pixels with small negative values of $R_{2}-R_{1}$ extending away from the line of clear water and ice-covered pixels represent thin cloud over ocean or partially ice-covered ocean. As the clouds thicken, the cloud-covered pixels tend to converge toward small $\left|R_{2}-R_{1}\right|$ and large $R_{2}$, regardless of the surface type. However, for this particular scene most of the clouds seem to be thin, in the sense that the signatures of the underlying surface are quite discernible.

Raschke [1987] found that thin clouds over snow and ice had values of $R_{2}-R_{1}$ less than $-\mathbf{0 . 0 6}$. This threshold was confirmed by a comprehensive analysis of the reflectivity difference in channels 1 and 2 of scenes that were exclusively ice, land, or ocean, as determined from their geographical location and maps of the ice boundaries. The same analysis suggested the thresholds shown in Figure 4 to classify pixels identified as being cloudy by Sakellariou's method as being thin cloud over land and over ocean. While the regions labelled 2 and 4 in Figure 4 will contain pixels that have surfaces that are predominantly ocean and ice/snow, respectively, region 4 may contain some fractions of water and region 2 may have small fractions of sea ice. All plots of the changes of $R_{2}-R_{1}$ with $R_{2}$ for regions of sea ice near the boundary of the ice reveal a well-defined linear arrangement of the pixels, with $R_{2}$ varying between 0.06 and 0.3 . Beyond this range there are clusters of pixels suggesting homogeneous surfaces of open water and ice at the low and high reflectivity ends of the line, respectively. Accordingly, in order to estimate the ice fractions within an AVHRR FOV, $R_{2}$ is interpolated between these limits. While the selection of the exact limits of the range of $R_{2}$ is not well defined, the results of the comparison of scene identification based on AVHRR and ERBE radiances that follows are insensitive to the details of the interpolation. In fact, they differ only slightly from results based on a classification in which all pixels lying on the line were considered to be $100 \%$ ice-covered. Region 3, labelled thick cloud, is the domain of reflectivity where the underlying surface for cloudy pixels cannot be identified unambiguously. These thresholds are valid for solar zenith angles less than $82^{\circ}$. At larger zenith angles over the ocean, both $R_{2}$ and $R_{2}-R_{1}$ can be large, and hence thin cloud over the ocean and over land may be indistinguishable. One further complication is the possibility that pixels in region 2 are, in fact, land partially covered by snow. To allow for this when making the scene identification for an ERBE pixel from the AVHRR data, the ERBE geotype is referred to in order to verify that the pixel is not land before it is classified as being thin cloud over ocean.

Figure $5 a$ shows results of the original Sakellariou scene identification algorithm for a sector of the Arctic on July 10 , 1985 , with much of the underlying surface obscured by cloud. In the results of the procedure described above (Figure $5 b$ ), the surface under a large portion of the cloud-covered region has been recognized as being covered by sea ice. It should be noted that fractional sea ice is not distinguished from solid ice in the images so as to enhance the contrast between the main scene types. Similarly, Figures $5 c$ and $5 d$ show a different sector of the Arctic on the same day, in which regions of the surface obscured by thin cloud are identified as being land, ocean, and ice. The good agreement between the ice edge found in Figure $5 b$ and that given by the Navy/NOAA Joint Ice Center map, redrawn in Figure 6, provides a useful verification of the results. Most importantly, the boundary of the sea ice shown in Figure $5 b$ agrees much more closely with the sea-ice map than does the ERBE specified sea-ice boundary, which in this region is at about $82^{\circ} \mathrm{N}$ (Figure 1). The regions of land identified in Figure 

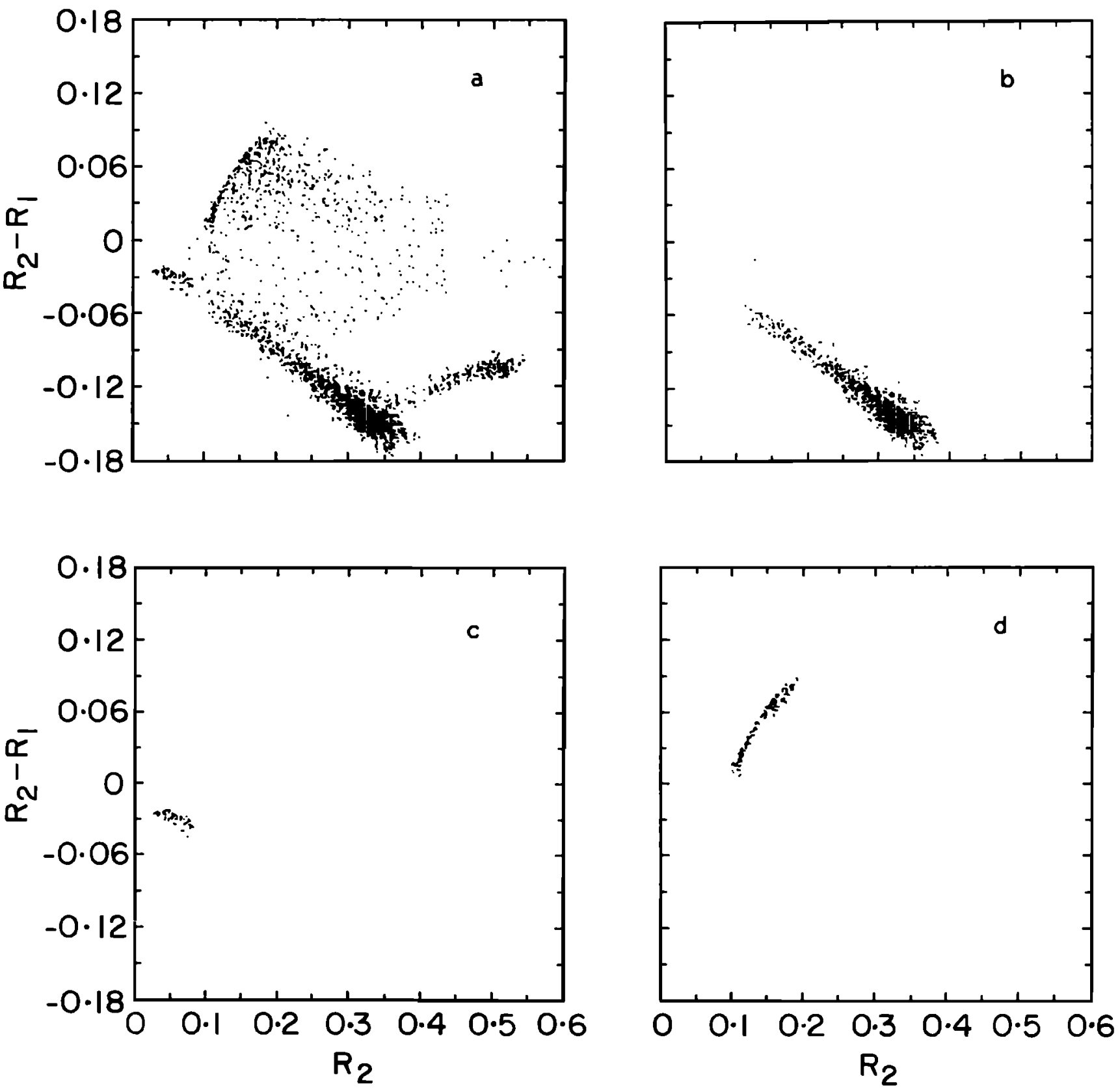

Fig. 3. Difference in reflectivity in channels 2 and 1 of the AVHRR plotted against the reflectivity in channel 2 from pass 2 on July 10, 1985, over the East Siberian Sea and the Siberian coast. (a) All scenes; (b) clear ice or snow; (c) clear ocean; (d) clear land.

$5 d$ agree well with the geography of the region and lead to further confidence in the ability of the algorithm to identify surface type under thin cloud. As an additional check on the reliability of the retrieval, it was verified that the fields are continuous in the sense that transitions from thin to thick clouds and vice versa are not related to changes in the nature of the underlying surface. By contrast, the boundary between overcast and mostly cloudy skies that parallels the $77.5^{\circ} \mathrm{N}$ latitude line in Figure $2 b$ is clear evidence that specification of the sea-ice boundary influences cloud classification by ERBE. Similarly, regions of sea ice are continuous across boundaries between clear skies and thin cloud. Finally, since the usefulness of the algorithm is dependent on the ratio of the number of cloudy pixels classified as having thin cloud to the number with thick cloud, it should be noted that for the summer cases that have been analyzed, over $80 \%$ of the polar clouds fall in the "thin" category.

By combining the information on cloud and surface type for the 64 AVHRR pixels that correspond to a single ERBE pixel, it is possible to produce a new classification of each ERBE pixel. The cloud cover is simply determined from the fraction of the 64 AVHRR pixels that are found to be cloudy. Following the ERBE classification of cloud amount [Suttles et al., 1988], if less than $5 \%$ of the AVHRR pixels are cloudy, the ERBE pixel is clear; if from $5-50 \%$ are cloudy, the ERBE pixel is partially cloudy; if 50 - 95\% are cloudy, the ERBE pixel is mostly cloudy; 


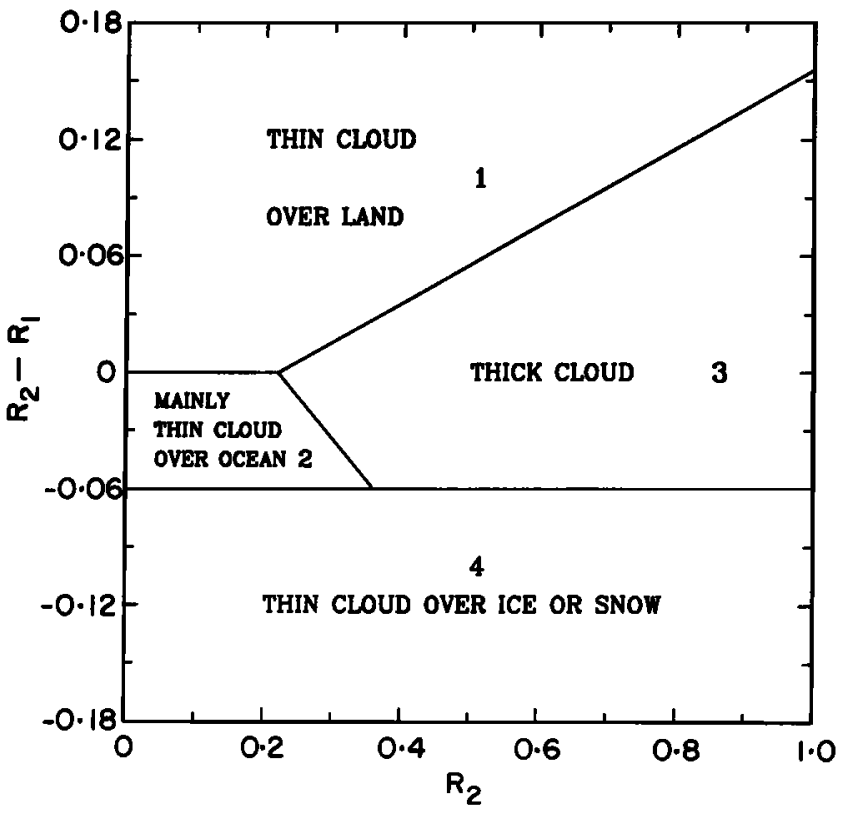

Fig. 4. Values of reflectivity in channels 1 and 2 of the AVHRR used to distinguish surfaces underlying thin cloud for those pixels classified as being cloudy by the method of Sakellariou et al. (submitted manuscript, 1990).

and if more than 95\% are cloudy, the ERBE pixel is classified as being overcast.

The nature of the surface is specified as belonging to one of six classes: land, ocean, ice/snow, and combinations of any two of the three pure surface types. The classification is based on the amounts of the two most abundant surface types found to be present in a particular ERBE pixel. If the most abundant surface type covers more than $95 \%$ of the surface, only that single surface type is taken to be present. If thick cloud covers less than 25\% of the ERBE pixel, the classification of the surface of the ERBE pixel is only dependent on the AVHRR pixels that are clear or have thin cloud. Otherwise, the clas- sification should also consider the surface type of the area covered by thick cloud. This is taken to be the surface type for that pixel, as specified by the ERBE algorithm, with the following modification. For an ERBE pixel that is not classified as being ice/snow, the area under thick cloud is assumed to have the same ice/snow fraction as the clear AVHRR pixels and the AVHRR pixels with thin cloud that are within the same ERBE FOV. If an ERBE pixel is prescribed as being ice/snow, the classification is assumed to be correct. The justification for this modification is that the ERBE scene specification tends to underestimate the amount of ice in regions with fractional ice cover. If the cloud cover is greater than $95 \%$ and more than $50 \%$ of the coverage is by thick cloud, no attempt is made to identify the surface and the pixel is taken to be overcast by thick cloud. The combination of four cloud conditions, six surface types, and the thick overcast class gives a total of 25 different kinds of ERBE scenes according to the present procedure.

\section{COMPARISON OF SCENES IDENTIFIED FROM ERBE AND AVHRR DATA}

\subsection{Surface Type}

The performance of the ERBE scene identification algorithm can be assessed by comparing it with the scene types deduced from AVHRR data. While the AVHRR-based scene types are not free from error, one can expect them to be more reliable than the ERBE-based scene types and hence to provide an useful measure of the performance of the ERBE algorithm. For the purpose of clarity, in the discussion that follows the AVHRR results are implicitly taken to be correct, although it is, of course, recognized that they do in fact contain error in the identification of surface type and cloud. An effective and informative way to compare the surface type prescribed by ERBE and that deduced from the AIMPR data is in terms of probability matrices [Coakley and Baldwin, 1988; Diekmann and Smith, 1989]. Three different matrices are defined:

$$
p_{1}(i, j)=\frac{n_{i j}}{N_{0 j}},
$$

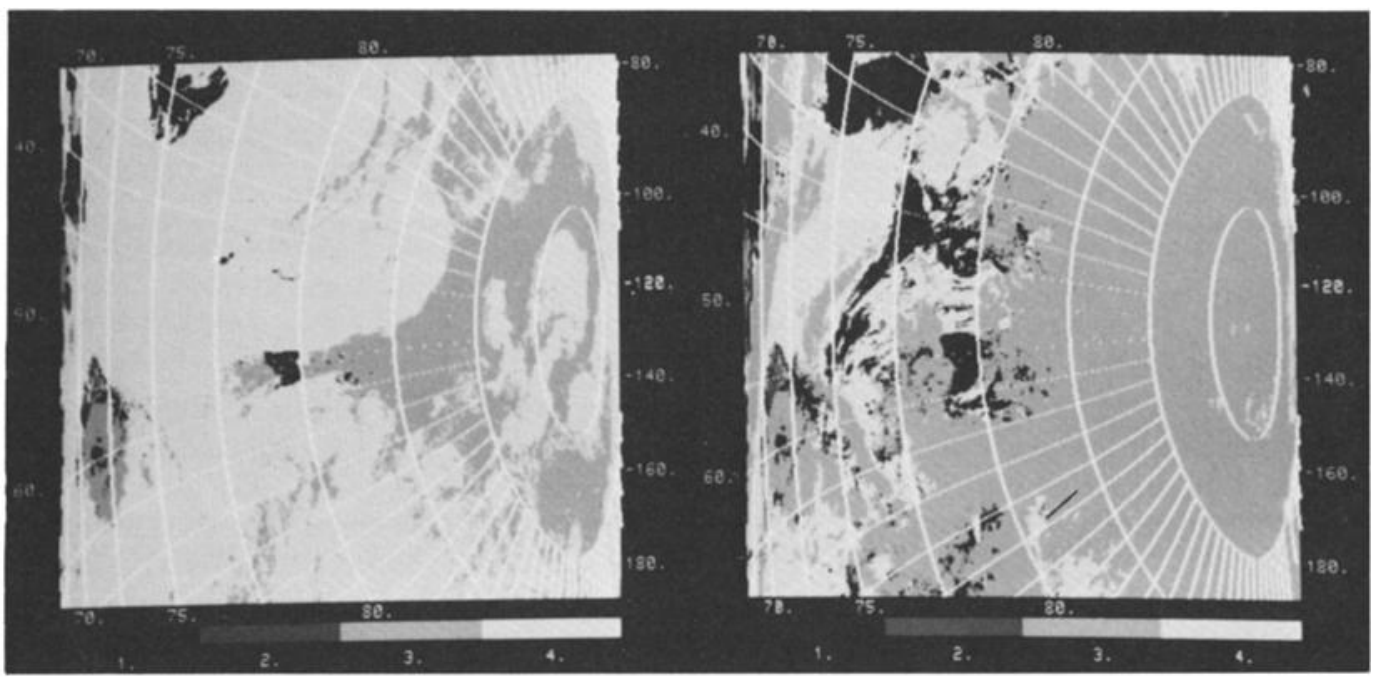

Fig. 5. (a) Scene types identified from AVHRR data from pass 3 on July 10, 1985. Shades have the same meaning as in Figure $2 a$. (b) Same as Figure $5 a$, but now geotypes under thin cloud have been identified. Shade 4 represents thick cloud. (c) Same as Figure $5 a$ but for a more southerly region from pass 5 on the same day. (d) Same as Figure $5 b$, but for the same region as in Figure $5 c$. 


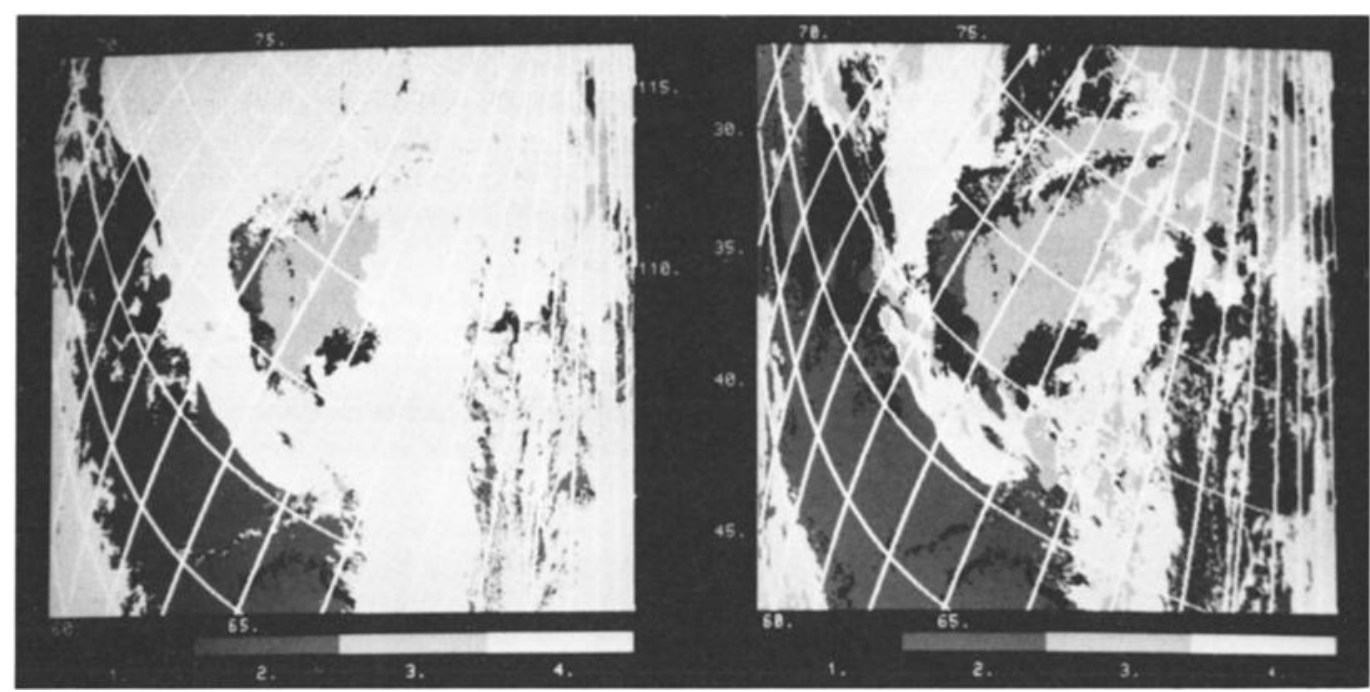

Fig. 5. (continued)

$$
\begin{aligned}
& p_{2}(i, j)=\frac{n_{j}}{N_{i 0}}, \\
& p(i, j)=\frac{n_{j}}{N}, \\
& N_{0 j}=\sum_{i=1}^{4} n_{i j}, \\
& N_{i 0}=\sum_{j=1}^{6} n_{i j}, \\
& N=\sum_{i=1 j-1}^{4} \sum_{i j}^{6} n_{i j}
\end{aligned}
$$

where $n_{i j}$ is the number of pixels assigned geotype $i$ by ERBE

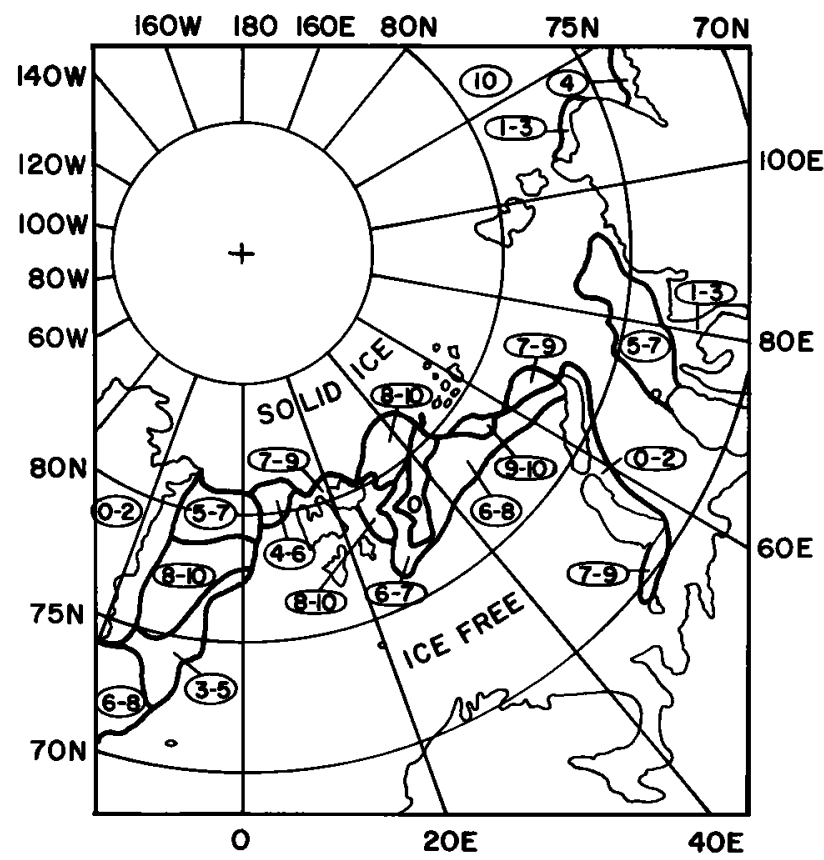

Fig. 6. Sea-ice concentration (in tenths) extracted from the sea-ice map referred to in Figure 1. and geotype $j$ from the analysis of the AVHRR data. The matrix $p_{1}$ gives the conditional probability that the actual geotype $j$ (according to the AVHRR data) is identified as geotype $i$ by ERBE, $p_{2}$ gives the conditional probability that geotype $i$ as assigned by ERBE is actually geotype $j$, and $p$ gives the joint probability of a particular pair of geotype identifications by the two methods and so gives an indication of the relative frequency of the various misclassifications.

To provide adequate statistics, all ERBE pixels north of $60^{\circ} \mathrm{N}$ on four days in July 1985 (July 1, 10, 19, and 29) for which the AVHRR classification was not thick overcast and for which the solar zenith angle did not exceed $82^{\circ}$ are included in the analysis, the results of which are given in Table 1 . Geotype classes 1-4 refer to ocean, land, ice/snow, and a mixture of ocean and land, respectively. The AVHRR classes $j=5,6$ are mixtures of ocean and ice, and land and snow.

The fact that the first two diagonal elements of $p_{1}$ are both close to $100 \%$ implies that almost all of the ocean and land geotypes are correctly prescribed by ERBE. The reverse, that pixels specified by ERBE as being ocean and land actually correspond to those geotypes, is not necessarily true. In fact, from $p_{2}$ it is seen that for only $46 \%$ of the pixels is the ERBE prescription of ocean correct. In the case of land, only $68 \%$ are correctly prescribed, but a further $18 \%$ are a mixture of land and snow according to the AVHRR algorithm. For the ice/snow geotypes the situation is opposite to that for ocean and land. Only $52 \%$ of the ice/snow pixels are correctly prescribed by ERBE, with most of the misidentified pixels being specified as ocean. On the other hand, of those pixels identified as being ice by ERBE, $81 \%$ are correct and a further $13 \%$ are a mixture of ice and ocean. These discrepancies can be understood as resulting from the prescribed ice edge for the ERBE geotype specification being too far north, as described earlier. The matrix $p$ demonstrates that the discrepancies are significant in that, for example, pixels misclassified by ERBE as being ocean when they are really ice/snow account for $10 \%$ of all the pixels analyzed.

\subsection{Clouds}

Probability matrices $\boldsymbol{P}_{1}$ and $\boldsymbol{P}_{2}$ similar to those for surface type can be defined to compare the AVHRR and ERBE retrievals 
TABLE 1. Geotype Probability Matrices $p_{1}, p_{2}$, and $p$ for the Region North of $60^{\circ} \mathrm{N}$ on July $1,10,19$, and 29, 1985

\begin{tabular}{|c|c|c|c|c|c|c|}
\hline \multirow{2}{*}{$\begin{array}{l}\text { ERBE } \\
\text { Geotype }\end{array}$} & \multicolumn{6}{|c|}{ AVHRR Geotype } \\
\hline & 1 & 2 & 3 & 4 & 5 & 6 \\
\hline & \multicolumn{6}{|c|}{ Conditional Probability Matrix $p_{1}$} \\
\hline 1 & 87.6 & 0.3 & 34.2 & 8.2 & 61.1 & 1.9 \\
\hline 2 & 2.4 & 96.3 & 7.9 & 27.7 & 1.5 & 88.5 \\
\hline 3 & 2.6 & 0.2 & 51.9 & 4.2 & 20.1 & 2.3 \\
\hline \multirow[t]{2}{*}{4} & 7.4 & 3.2 & 6.0 & 59.9 & 17.3 & 7.3 \\
\hline & \multicolumn{6}{|c|}{ Conditional Probability Matrix $p_{2}$} \\
\hline 1 & 46.2 & 0.2 & 29.3 & 1.8 & $22.1^{2}$ & 0.4 \\
\hline 2 & 1.2 & 67.7 & 6.5 & 5.8 & 0.5 & 18.3 \\
\hline 3 & 2.5 & 0.2 & 81.4 & 1.7 & 13.3 & 0.9 \\
\hline \multirow[t]{2}{*}{4} & 12.0 & 7.2 & 16.0 & 40.7 & 19.2 & 4.9 \\
\hline & \multicolumn{6}{|c|}{ Joint Probability Matrix p } \\
\hline 1 & 15.8 & 0.1 & 10.1 & 0.6 & 7.6 & 0.1 \\
\hline 2 & 0.4 & 24.3 & 2.3 & 2.1 & 0.2 & 6.6 \\
\hline 3 & 0.5 & 0.0 & 15.3 & 0.3 & 2.5 & 0.2 \\
\hline 4 & 1.3 & 0.8 & 1.8 & 4.5 & 2.1 & 0.5 \\
\hline
\end{tabular}

The AVHRR geotypes 1-4 are the same as the ERBE geotypes 1-4, namely, ocean, land, ice/snow, and ocean-land mixture, respectively. AVHRR geotypes 5 and 6 are ocean-ice mixture and land-snow mixture.

of cloud, where the rows and columns are labelled by the cloud amount class, with $i, j=1-4$ representing clear, partially cloudy, mostly cloudy, and overcast skies, respectively. The four diagonal elements of each of the conditional probability matrices $P_{1}$ and $P_{2}$, evaluated independently for each surface type and for all surfaces taken together, are given in Table 2 . Only observations for which the AVHRR and ERBE geotypes agree are included in the probability matrices. The matrices $P_{1}$ and $P_{2}$ are equivalent to $p_{1}$ and $p_{2}$, respectively, in that diagonal elements of $P_{1}$ give the fraction of the pixels with a particular cloud condition that are correctly identified by the ERBE algorithm, whereas the diagonal elements of $P_{2}$ give the probability that a cloud condition identified by ERBE is correct. Pixels for which both the AVHRR and ERBE geotypes are ocean that are identified as being overcast by the ERBE algorithm are almost without exception (98.4\%) correct. The reverse is not true, with only $38 \%$ of the overcast pixels over ocean actually being classified as overcast by ERBE. Similar results hold for overcast conditions over land and mixtures of ocean and land. Over ice/snow, $85 \%$ of the overcast pixels are so identified by ERBE, but only $46 \%$ of the pixels identified by ERBE as being overcast are in fact fully cloud-covered. The estimation of partially and mostly cloudy conditions is even less satisfactory. More important from the point of view of cloud-forcing studies are errors in the identification of clear pixels. From matrix 2 it is seen that the fraction of the pixels that are identified as being clear by ERBE that are really cloud contaminated according to the AVHRR varies from $58 \%(100 \%-42 \%)$ over land-ocean to $14 \%$ (100\%-86\%) over land.

The diagonal elements of the joint probability matrices give the joint probabilities of a particular sky condition being identified by both the ERBE and AVHRR algorithms. The offdiagonal elements give the joint probability of a particular type of misidentification, with the seriousness of the misidentification depending on the distance of the element in question from the diagonal. Error indices from 0 to 3 are assigned as shown below, with positive or negative indices indicating that the cloud amount deduced from the AVHRR measurements is greater or smaller than the ERBE amount, respectively [Diekmann and Smith, 1989].

$$
e=\left(\begin{array}{cccc}
0 & 1 & 2 & 3 \\
-1 & 0 & 1 & 2 \\
-2 & -1 & 0 & 1 \\
-3 & -2 & -1 & 0
\end{array}\right)
$$

To determine if there is any tendency for overestimation or underestimation of cloud amount by ERBE for particular surface types, the joint probability matrix is calculated for each of the four surface types separately for all pixels for which the surface type identification from the AVHRR data and from ERBE agree. The results are plotted in Figures $7 a-d$ in the form of histograms of the frequency of occurrence of error index.

The values of $P, A$, and $S$ that are given in the diagrams are figures of merit that serve to evaluate the ERBE cloud detection scheme quantitatively . $P$ is the Preisendorfer moment, also referred to as the "moment of misclassification" [Diekmann and Smith, 1989], which is defined by

$$
P=\frac{1}{N} \sum_{i-1}^{4} \sum_{j=1}^{4}\left|e_{i j}\right| n_{i j},
$$

with $P$ ranging from 0 to 3 as the error in the ERBE cloud amount classification increases.

An alternative figure of merit is the skill score used by Coakley and Baldwin [1988] to measure the accuracy of the

\begin{tabular}{|c|c|c|c|c|c|c|c|c|}
\hline \multirow[b]{2}{*}{ Geotype } & \multicolumn{4}{|c|}{ Diagonal Elements of $P_{1}$} & \multicolumn{4}{|c|}{ Diagonal Elements of $P_{2}$} \\
\hline & CLR & PCD & MCD & OVC & CLR & PCD & MCD & ovc \\
\hline Ocean & 70.5 & 43.1 & 76.7 & 37.9 & 82.9 & 36.7 & 14.3 & 98.4 \\
\hline Land & 52.5 & 59.6 & 70.8 & 51.8 & 86.2 & 40.1 & 33.9 & 93.2 \\
\hline Ice/Snow & 36.9 & 0.0 & 0.0 & 85.7 & 46.0 & 0.0 & 0.0 & 46.5 \\
\hline Land-Ocean & 57.0 & 43.3 & 71.5 & 44.7 & 42.1 & 41.6 & 23.8 & 97.6 \\
\hline All scenes & 40.8 & 32.4 & 54.9 & 50.1 & 60.4 & 38.8 & 28.3 & 67.6 \\
\hline
\end{tabular}

Table 2. Central Diagonal Elements of Conditional Probability Matrices $P_{1}$ and $P_{2}$

In $\boldsymbol{P}_{1}$ these elements give the fraction of pixels in a particular cloud class that are correctly classified by ERBE. Elements are extracted from matrices computed for each of the four geotypes separately and for all geotypes taken together. In $P_{2}$ the central diagonal elements give the fraction of pixels in a particular cloud class that are actually correct. The data are from all passes on July $1,10,19$, and 29,1985 , in the region north of $60^{\circ} \mathrm{N}$. 

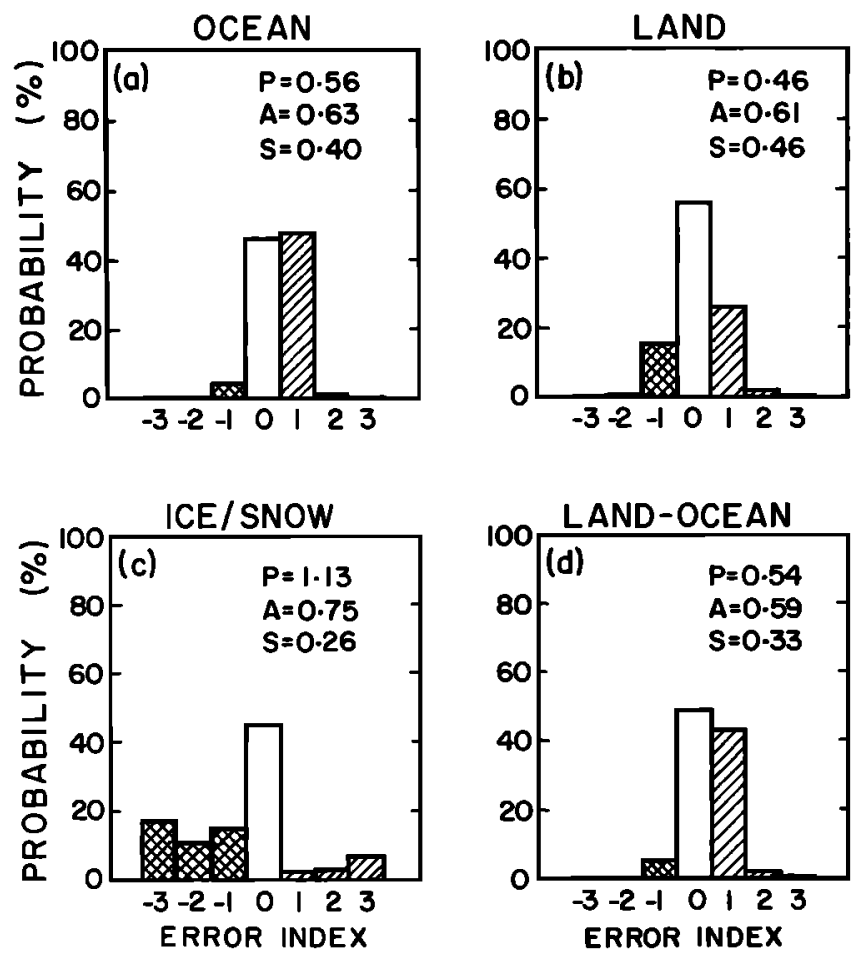

Fig. 7. Histograms of error index in the identification of cloud class by ERBE relative to the class identified from AVHRR data for the region north of $60^{\circ} \mathrm{N}$ on July 1,10, 19 and 29,1985 , over $(a)$ ocean, (b) land, $(c)$ ice/snow, and $(d)$ land-ocean mixture. Negative indices indicate an overestimation by ERBE. The values of $P, A$, and $S$ that are given in the diagrams are figures of merit that serve to quantitatively evaluate the ERBE cloud detection scheme.

ERBE retrieval, $A$, relative to the results that would be expected by chance, $E$. It is defined by

$$
\begin{gathered}
S=\frac{A-E}{1-E}, \\
A=\sum_{j=1}^{4} P_{1}(j, j) f(j), \\
E=\sum_{j=1}^{4} f^{2}(j), \\
f(j)=\frac{N_{0 j}}{N},
\end{gathered}
$$

where $P_{1}(i, j)$ is the conditional probability that a pixel in cloud class $j$ is identified as being class $i$ by $E R B E$, and $f(j)$ is the relative frequency of class $j$ according to the AVHRR analysis. The accuracy, $A$, gives the probability that ERBE correctly identifies the cloud class, and $E$ depends on the frequency distribution of the four cloud classes. If $S=0$, the ERBE algorithm performs no better than a random selection constrained to have the same frequency distribution of cloud classes as the actual distribution, while $S=1$ implies perfect correspondence between ERBE and AVHRR results. The parameters $P$ and $S$ evaluate different aspects of the ERBE cloud classification, $S$ emphasizing the frequency of correct identification and $P$ taking into account the degree of misidentification, and so the ranking of performance according to $P$ and $S$ is not necessarily the same.
It is noted from Figure 7 that for all geotypes, between $40 \%$ and $60 \%$ of the pixels are assigned to the correct cloud class by ERBE. However the different geotypes show different biases in the distribution of the errors: ERBE tends to underestimate cloud amount over ocean and land-ocean and overestimate cloud amount over ice/snow. The strong underestimation of cloud cover by one class over the ocean is mainly accounted for by overcast pixels that are classified by ERBE as being only mostly cloud covered. In the Arctic in summer, the MLE method relies substantially on the shortwave observation rather than the longwave measurement because of the small difference in the mean thermal radiances of the surface and clouds compared to their standard deviations. The shortwave radiance means and standard deviations are latitude independent. Polar clouds are usually thinner than clouds at lower latitudes, so thresholds that are appropriate for the whole globe will tend to underestimate cloud amount in the polar regions over low albedo surfaces. The bias is somewhat weaker over purely land surfaces. Underestimation of cloud amount by one class for land surfaces is also primarily due to overcast pixels, $45 \%$ of which are identified by ERBE as being mostly cloudy in contrast to $60 \%$ for ocean surfaces. Less underestimation of cloud amount over land than over ocean perhaps occurs because the lands lie in the southern portions of the domain, where the clouds could be thicker and hence the contrast in albedo is greater, but more likely it occurs because the thermal contrast is greater. Apart from an underestimation of cloud over land, however, there is a significant overestimation of cloud by one class that arises from $45 \%$ of the clear pixels being misclassified as being partially cloudy by ERBE. Only two cloud classes, overcast or clear, are allowed by ERBE over ice/snow surfaces, so the error histogram in Figure $7 c$ does not have the same significance as it does for the other underlying surfaces. The columns with error indices of $-1,-2$ and -3 , for example, actually represent the probabilities that clear pixels are classified by ERBE as being partly cloudy, mostly cloudy, and overcast, respectively. It follows from Figure $7 c$ that clear pixels are more likely to be misidentified than overcast pixels over ice/snow surfaces.

Overall, the determination of cloud class by the ERBE is found to be most successful over land and least successful over ice/snow in terms of both the Preisendorfer moment and the skill score $S$. It should be noted that if the cloud classes determined by the AVHRR and ERBE are compared for all pixels, without the constraint of the underlying surface being the same classification by the two methods, the ERBE cloud identification shows even less skill.

\section{EFFECT OF SCENE MISIDENTIFICATION ON CLOUD FORCING}

The errors in the ERBE scene identification discussed above may lead to significant errors in the determination of cloud forcing in the Arctic. Incorrect scene identification will lead to the use of the wrong angular dependence models to convert the radiances to irradiances, and incorrectly distinguishing between clear and cloudy scenes will directly result in errors in the determination of cloud forcing. In this section the AVHRR scene identification is used to select the appropriate ADM to derive fluxes from the ERBE-measured radiances and to identify clear scenes. The cloud forcing is then computed and compared with values determined exclusively from ERBE measurements. Only 4 days of AVHRR data, namely July 1, 10, 19 and 29, 1985, were used. Therefore results should not be 
interpreted in any climatological sense, but only used to give an indication of the reliability of the cloud-forcing determination in the Arctic based solely on ERBE data.

\subsection{Daily Mean Fluxes}

Because of the higher spatial resolution of the AVHRR data, the AVHRR based classification of scenes contains two additional classes of cloud over ice, namely, partly cloudy over ice and mostly cloudy over ice, and two additional mixed surface types, land and ice/snow, and ocean and ice/snow. Angular models for mixed scenes are obtained from the weighted average of the two ERBE pure scene ADMs:

$$
R_{m}=\frac{w M_{1}\left(\theta_{0}\right) R_{1}\left(\theta_{0}, \theta, \phi\right)+(1-w) M_{2}\left(\theta_{0}\right) R_{2}\left(\theta_{0}, \theta, \phi\right)}{w M_{1}\left(\theta_{0}\right)+(1-w) M_{2}\left(\theta_{0}\right)},
$$

where $w$ is the fractional area of homogeneous scene $1 ; \mathbf{M}\left(\theta_{0}\right)$ is the ERBE-estimated flux for solar zenith angle $\boldsymbol{\theta}_{0}$; and $R\left(\theta_{0}, \theta, \phi\right)$ is the $A D M$ with viewing zenith angle $\theta$ and relative azimuth $\phi$. This equation is similar to the formula used by Suttles et al. [1988, 1989] to obtain the ADM for land-ocean mixtures, but in Suttles's formula the only weighting factor is $M\left(\theta_{0}\right)$. Here there is additional weighting by $w$, which is obtained from the AVHRR analysis.

More than half of the region north of $67.5^{\circ} \mathrm{N}$ is covered by each satellite pass. Since there are 14 passes per day, each point of the surface is viewed between seven and 14 times, thus allowing the determination of daily mean fluxes by directly integrating fluxes over solar zenith angle.

\subsection{Cloud Radiative Forcing}

The cloud forcing, $C$, is defined as the difference in the net daily fluxes for all sky conditions, $L_{\mathrm{cld}}$, and for clear skies, $L_{\mathrm{clr}}$, respectively.

$$
\begin{gathered}
C-L_{c l d}-L_{c l r}, \\
L_{c l r}-F_{0}-S_{c l r}-E_{c l r}-S_{c l r}^{\prime}-E_{c l r}, \\
L_{c l d}=F_{0}-S_{c l d}-E_{c l d}-S_{c l d}^{\prime}-E_{c l d},
\end{gathered}
$$

where $F_{o}, S$ and $E$ are the daily mean incoming solar, outgoing solar, and outgoing longwave irradiances, respectively, and $S^{\prime}$ is absorbed clear irradiance. The cloud forcing can be split into shortwave $\left(C_{s}\right)$, and longwave $\left(C_{l}\right)$, components:

$$
\begin{gathered}
C=C_{s}+C_{l}, \\
C_{s}=S_{c l r}-S_{c l d}, \\
C_{l}-E_{c l r}-E_{c l d *}
\end{gathered}
$$

The fluxes for the 4 days were grouped into nine latitude belts, each $2.5^{\circ}$ wide, starting at $67.5^{\circ} \mathrm{N}$. Within each latitude belt the data are grouped again, one group containing all the data and others containing the data from clear pixels of each surface types. The grouping of clear pixles according to the nature of the underlying surface is necessary because the occurrence of cloud is correlated with the underlying surface geotype. For instance, the cloud amount over much of Greenland is considerably lower than the average cloud amount at the same latitude [Vowinckel and Orvig, 1970]. A similar from the scene and cloud determinations from the present data, with clear skies occurring preferentially over ice/snow surfaces.
Therefore simply averaging the clear-sky fluxes from all clear pixels within a particular latitude belt would bias the zonal mean clear-sky flux in favor of the high-albedo ice/snow surface regions. To avoid this bias, mean clear-sky fluxes are obtained for each geotype and the zonal mean is obtained by weighting the value for each surface type by its fractional area within the latitude belt.

\subsection{Comparison of Results Based on AVHRR and ERBE Scene Identifications}

Figure 8 shows the meridional variation of the zonal mean absorbed solar fluxes and outgoing longwave fluxes under all sky conditions, with $\mathrm{ADMs}$ based on scene identification from the AVHRR (Figure 8a) and ERBE (Figure $8 b$ ). The good agreement in the two plots shows that the zonal mean fluxes are
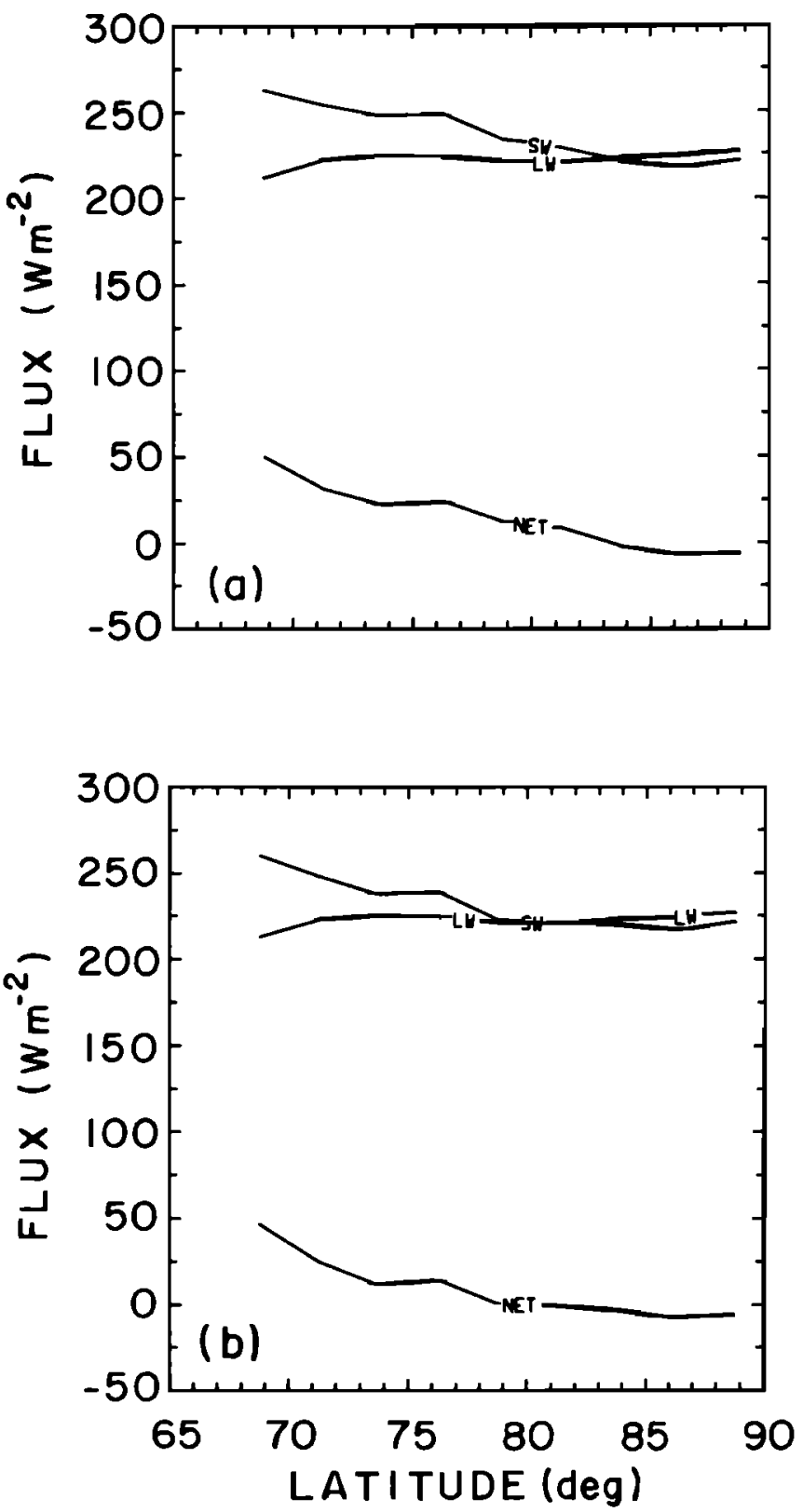

Fig. 8. Average meridional variation of the shortwave absorbed flux (SW), outgoing longwave flux (LW), and net flux (NET), for the 4 days in July 1985, and calculated from ERBE-measured radiances and scene types identified by ( $a$ ) AVHRR and ( $b$ ) ERBE. 
insensitive to the scene identification. The similarity in the absorbed solar fluxes can be explained by the similarity in the ADMs for ice/snow and cloud and their high albedos, whereas the similarity in the longwave fluxes is due to their similar temperatures. The longwave flux has very little meridional variation, while the shortwave-absorbed flux decreases with increasing latitude. Radiation has a weak heating effect in the Arctic for the period considered here except poleward of $83^{\circ} \mathrm{N}$, where the multiyear ice is sufficiently abundant that the shortwave heating is balanced by longwave cooling.

When the zonal mean fluxes for clear skies are compared (Figure 9), it is seen that longwave fluxes are still very similar, but now there is a considerable difference in the shortwave fluxes. The absorbed shortwave flux based on the AVHRR scene identification is smaller than that based on the ERBE scene identification in the lower latitudes of the Arctic and is higher in the high-latitude region. The AVHRR-based flux decreases fairly smoothly with increasing latitude, whereas the ERBE-based flux decreases sharply between $81^{\circ}$ and $83^{\circ} \mathrm{N}$.

Figure 10 shows the meridional variations of shortwave, longwave, and net cloud forcing deduced from ERBE-measured
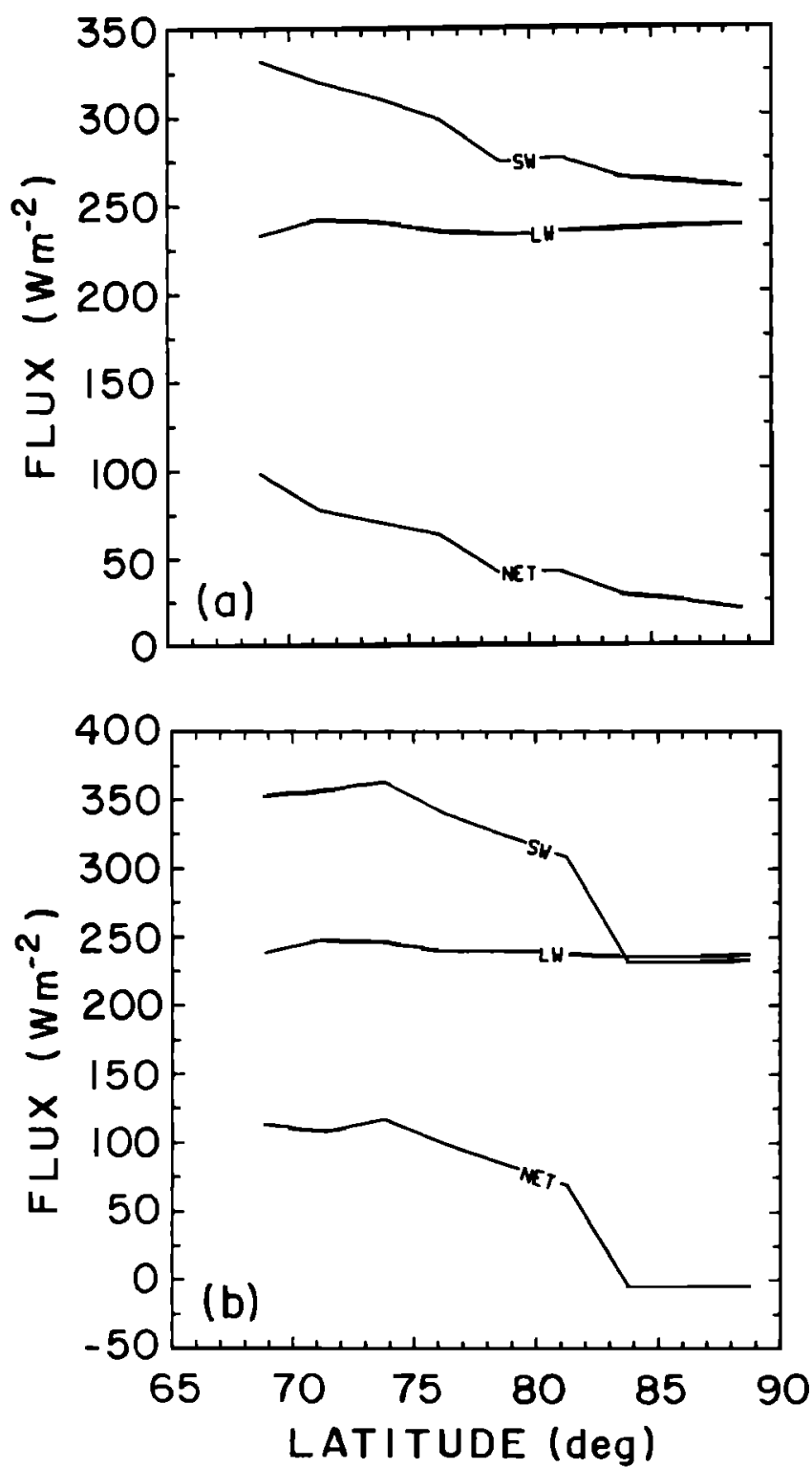

Fig. 9. Same as Figure 8, but for clear regions only.

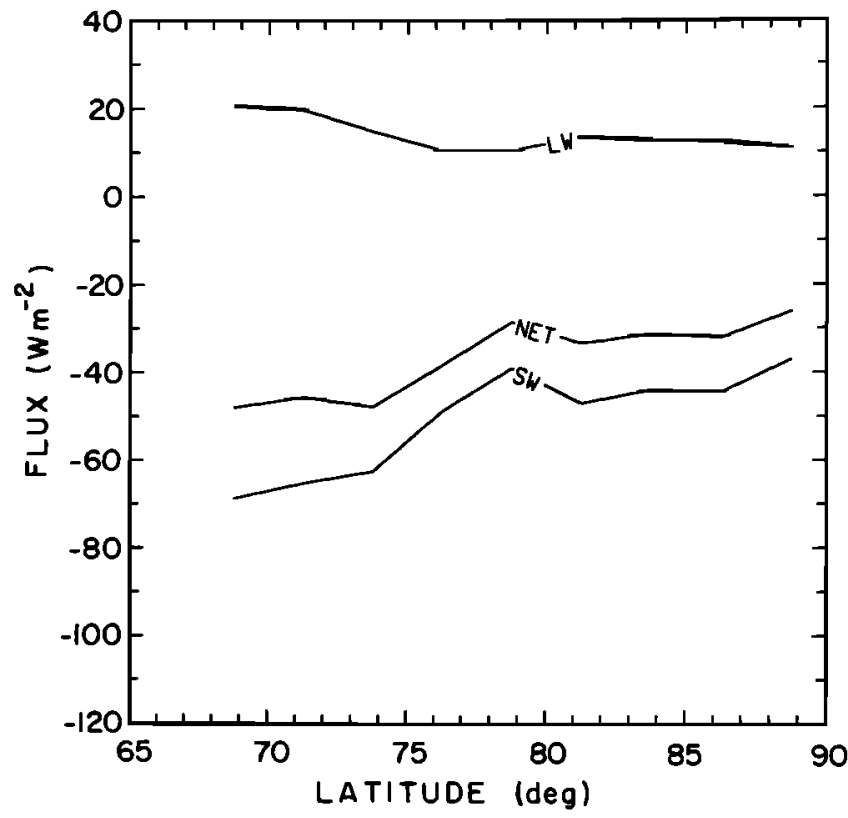

Fig. 10. Average meridional variation of shortwave, longwave, and net cloud forcing computed from ERBE radiances and scene types identified by the AVHRR for the 4 days in July 1985.

radiances and AVHRR scene identification. It is evident that the negative shortwave cloud forcing is much larger in magnitude than the positive longwave cloud forcing, leading to negative net cloud forcing in the Arctic. In contrast to the small variation of longwave cloud forcing with latitude, the magnitudes of the shortwave and net cloud forcing decrease toward the pole as the ice fraction increases. The peak in shortwave and net cloud forcing between $74^{\circ}$ and $81^{\circ} \mathrm{N}$ reflects the influence of the Greenland ice cap.

As shown in Figure 11, scene misidentification by ERBE has a significant effect on the derived cloud forcing. Since the longwave fluxes based on AVHRR and ERBE scene identifications are similar, the longwave forcing is insensitive to the scene identification procedure. However, the significant differences in the clear-sky shortwave fluxes deduced from the two methods results in equivalent differences in the shortwave and net cloud forcing which are as large as $50 \mathrm{~W} \mathrm{~m}^{-2}$. These discrepancies result from the sharp sea-ice boundary that is included in the ERBE scene identification. The boundary, which is north of the region of fractional sea ice, has the effect that much of the high-albedo fractional sea ice located south of $80^{\circ} \mathrm{N}$ (Figure 1) is interpreted as cloud over ocean and so is not included in the determination of the clear-sky flux. Thus the ERBE zonally averaged clear sky absorbed solar flux excludes much of the region that is covered by sea ice and hence overestimates the average absorbed solar radiation. This explanation is confirmed by the increasing fraction of clear ice/snow covered pixels identified by the AVHRR that are identified by ERBE as being cloud-covered as the latitude decreases (Figure 12). As the amount of fractional sea ice diminishes south of $74^{\circ} \mathrm{N}$ and north of $79^{\circ} \mathrm{N}$, the ERBE and AVHRR determinations of cloud forcing converge. Poleward of $82^{\circ} \mathrm{N}$ the ERBE cloud forcing becomes more positive than the AVHRR values. In this region sea ice is correctly prescribed by ERBE. However, as the latitude increases, the fraction of the pixels identified as being cloud-covered by AVHRR that are 

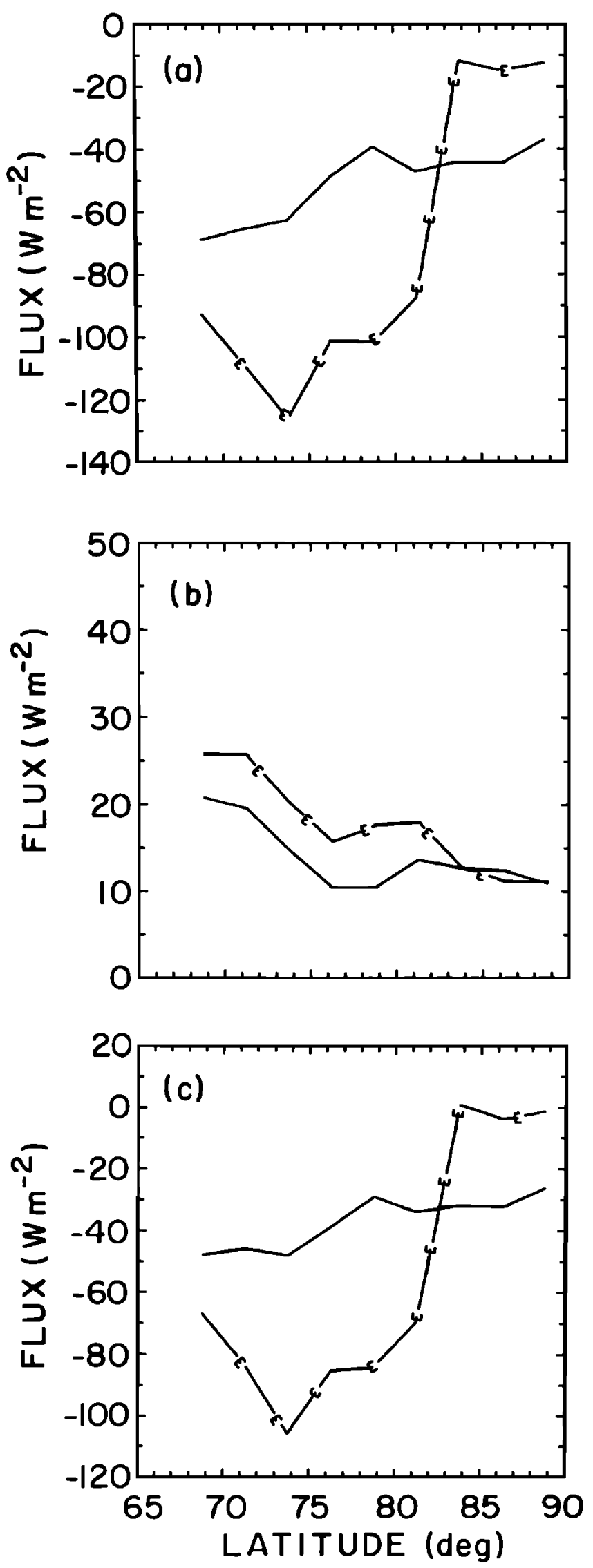

Fig. 11. Comparisons of the average cloud forcing based on scene identification deduced from AVHRR data and ERBE data (denoted by $E$ ) for the 4 days in July 1985: (a) shortwave, (b) longwave, and (c) net.

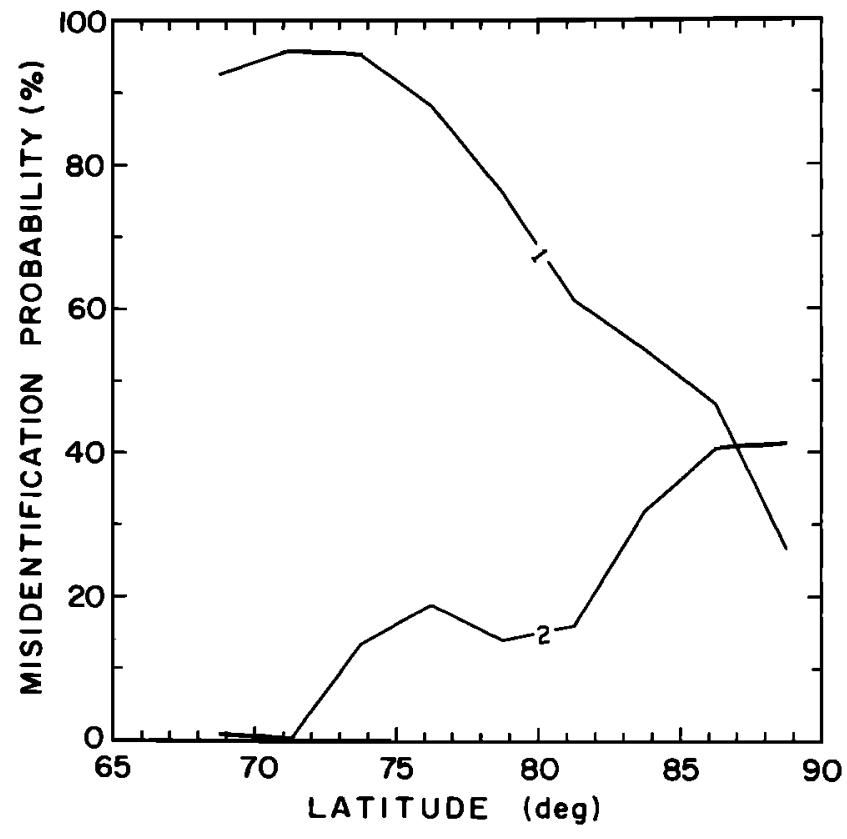

Fig. 12. Average meridional variation of the probabilities that a clear ice/snow pixel is identified as being cloudy by ERBE (denoted by curve labelled 1), and that a cloudy pixel identified by the AVHRR is identified as being clear ice/snow by ERBE (curve labelled 2), for the 4 days in July 1985.

misidentified as being clear ice by ERBE increases (Figure 12). This could well account for an underestimation of the absorbed solar flux under clear skies.

The southern region, where the net cloud forcing determined from the AVHRR data is larger than that from the ERBE data, dominates the cloud forcing for the whole domain. This leads to a domain mean net cloud forcing based on AVHRR scenes that is $33 \mathrm{~W} \mathrm{~m}^{-2}$ larger than that based on ERBE scenes. The components of cloud forcing from the AVHRR and ERBE data are compared for the whole domain in Table 3.

From the AVHRR data the average cloud forcing over the whole domain can be determined for each geotype (Table 4). As expected, shortwave cloud forcing over land and ocean have the largest magnitudes, and over ice the magnitude is smallest. The largest longwave forcing is over land, where temperatures are warmest, and the smallest forcing is over ice. The net cloud forcing is negative for all geotypes.

The standard deviations of the mean zonal fluxes $S_{\mathrm{clr}}, S_{\mathrm{cld}}, E_{\mathrm{cl} r}$, and $E_{\mathrm{cld}}$, as well as net cloud forcing calculated from the standard deviations of the fluxes from pixels of the same geotype, cloud cover, and solar zenith angle are small, being always less than $5.5 \mathrm{~W} \mathrm{~m}^{-2}$. These values, however, do not account for the uncertainties resulting from misidentification of geotype, cloud cover, and the angular dependence models.

\section{CONCLUSIONS}

Cloud radiative forcing is a useful way of quantifying the effect of clouds on the Earth's radiation budget. To determine the cloud forcing, correct scene identification is required in order to use the appropriate ADM to convert measured radiance to irradiance, and to distinguish between clear and cloud-contaminated pixels. Scene identification is a particular 
Table 3. Comparison of the Domain-Mean Shortwave, Longwave, and Net Cloud Forcing Derived From Scene Identification Based on AVHRR and ERBE Data

\begin{tabular}{lccc}
\hline Scene ID & $\begin{array}{c}\text { Shortwave } \\
\mathrm{W} \mathrm{m} \mathrm{m}^{-2}\end{array}$ & $\begin{array}{c}\text { Longwave } \\
\mathrm{W} \mathrm{m}^{-2}\end{array}$ & $\begin{array}{c}\text { Net } \\
\mathrm{W} \mathrm{m}^{-2}\end{array}$ \\
\hline AVHRR & -56.0 & 15.4 & -40.6 \\
ERBE & -94.1 & 20.3 & -73.8 \\
\hline
\end{tabular}

Data is from all passes on the 4 days in July 1985 in the region north of $67.5^{\circ} \mathrm{N}$.

Table 4. Shortwave, Longwave, and Net Cloud Forcing Over Different Geotypes Determined From AVHRR Data

\begin{tabular}{lrrrrrr}
\hline & Ocean & Land & $\begin{array}{r}\text { Ice/ } \\
\text { Snow }\end{array}$ & $\begin{array}{r}\text { Ocean- } \\
\text { Land }\end{array}$ & $\begin{array}{r}\text { Ocean- } \\
\text { Ice }\end{array}$ & $\begin{array}{r}\text { Land } \\
\text { Snow }\end{array}$ \\
\hline & & & & & & \\
SWCF & -120.4 & -108.5 & -35.3 & -115.6 & -80.5 & -69.1 \\
LWCF & 19.7 & 33.1 & 9.6 & 25.3 & 12.6 & 15.2 \\
NETCF & -100.7 & -75.4 & -25.7 & -90.3 & -67.9 & -53.9
\end{tabular}

All measurements are in units of $\mathrm{W} \mathrm{m}^{-2}$. Data is from all passes on the 4 days in July 1985 in the region north of $67.5^{\circ} \mathrm{N}$.

problem at high latitudes, where snow and ice backgrounds and clouds may easily be confused.

Surface geotypes and clouds obtained from the ERBE scene identification algorithm differ significantly from the geotype identification and cloud classification deduced from AVHRR radiances in the Arctic region in summer. The multichannel AVHRR radiances have a greater potential to distinguish between different surface types, and between clouds and the underlying surface. In the absence of suitable ground truth more confidence must be given to the AVHRR identification when the ERBE and AVHRR results differ.

Comparison of the geotypes given by ERBE with those deduced from AVHRR measurements suggest that most of the regions specified by ERBE as having an ice/snow surface are correct. However, there are large areas that ERBE specifies as being ice-free ocean that are actually partially or totally covered by ice. The discrepancy results from the specified ice/snow open ocean boundary being too far north and the absence of a transition zone from solid ice to open ocean. Over the partially ice-covered but clear ocean, ERBE identifies regions of high reflectivity as being cloudy which results in an overestimation of cloud amount. Over regions where both the AVHRR analysis and ERBE identify the underlying surface as being land or ocean, ERBE underestimates the cloud amount compared to the AVHRR algorithm. In cases where both methods identify the underlying surface as being ice or snow, ERBE overestimates cloud amount.

Two sets of fluxes are derived from the ERBE-measured radiances: one from bidirectional models selected according to the AVHRR-determined scene types and the other according to ERBE scene types. Longwave cloud forcing determined from the two sets of fluxes and scene types is similar, but differences in the clear-sky fluxes produce appreciable differences in the shortwave cloud forcing. The magnitude of the negative shortwave cloud forcing based on the ERBE scene identification is overestimated over most of the Arctic, with the largest differences about $50 \mathrm{~W} \mathrm{~m}^{-2}$ occurring in the area between $73^{\circ}$ and $82^{\circ} \mathrm{N}$, where fractional sea-ice has the most influence. Further north, where the surface is predominantly ice-covered, the magnitude of the cloud forcing obtained from ERBE is smaller than that from the AVHRR owing to the difficulty in identifying clouds over the high-reflectivity, cold background. The magnitude of the difference is about one half that in the southern portion of the Arctic, and the area is substantially smaller, so that the southern region dominates the average cloud forcing over the whole region.

Although the magnitudes of the differences in cloud forcing deduced from the two scene identification approaches are characteristic of the particular meteorological and surface conditions present on the 4 days studied, the present results do point out the potentially large errors that may result from the determination of cloud forcing at high latitudes from ERBE data.

Acknowledgments. We are very grateful to Roger Davies for providing the ERBE data and for his helpful comments. This work benefited from discussions with N. Sakellariou. J. L. Green of the World Data Center $\mathrm{A}$ is gratefully acknowledged for providing the angular dependence models. The authors wish to express their thanks to A. Schwartz for computing assistance and to U. Seidenfuss for drawing some of the plots. This work was partially supported by grants from the Canadian Atmospheric Environment Service and the Natural Sciences and Engineering Research Council.

\section{REFERENCES}

Allen, R. C. Jr., P. A. Durkee and C. H. Wash, Snow/cloud discrimination with multispectral satellite measurements, J. Appl. Meteorol, 29, 994-1004, 1990.

Bowker, D. E., R. E. Davis, D. L. Myrick, K. Stacy, and W. T. Jones, Spectral reflectances of natural targets for use in remote sensing studies, NASA Ref. Publ. 1139, 181 pp., 1985. (Available from National Aeronautics and Space Administration, Code NTT-4, Washington, D.C.)

Cess, R. D., and G. L. Potter, Exploratory studies of cloud radiative forcing with a general circulation model, Tellus, 39A, 460-473, 1987. Charlock, T. P., and V. Ramanathan, The albedo field and cloud radiative forcing produced by a general circulation model with internally generated cloud optics, J. Atmos. Sci, 42, 1408-1429, 1985. Coakley, J. A., Jr., and D. G. Baldwin, Tests of ERBE scanner point spread function, narrow- to broadband radiance conversions and ERBE scene identification, report for 23rd ERBE Science Team Meeting, NASA Langley Res. Cent., Hampton, Va., 1988.

Comiso, J. C., and H. J. Zwally, Concentration gradients and growth/decay characteristics of the seasonal ice cover, J. Geophys. Res., 89, 8081-8103, 1984.

Davies, $\mathbf{R}$., Reflected solar radiances from broken cloud scenes and the interpretation of scanner measurements, J. Geophys. Res., 89, 12591266, 1984.

Diekmann, F. J., and G. L. Smith, Investigation of scene identification algorithms for radiation budget measurements, J. Geophys. Res., 94, 3395-3412, 1989.

Ebert, E., Analysis of polar clouds from satellite imagery using pattern recognition and a statistical cloud analysis scheme, J. Appl. Meteorol. 28, 382-399, 1989.

Gesell, G., An algorithm for snow and ice detection using AVHRR data, An extension to the APOLLO software package, Int. J. Remote Sens., 10, 897-905, 1989.

Grenfell, T. C., and G. A. Maykut, The optical properties of ice and snow in the Arctic basin, J. Glaciol., 18, 445-463, 1977.

Grenfell, T. C., and D. K. Perovich, Spectral albedos of sea ice and incident solar irradiance in the Southern Beaufort Sea, J. Geophys. Res., 89, 3573-3580, 1984.

Harrison, A. R., and R. M. Lucas, Multi-spectral classification of snow 
using NOAA AVHRR imagery, Int. J. Remote Sens, 10, 907-916, 1989.

Hartmann, D. L., V. Ramanathan, A. Berroir, and G. E. Hunt, Earth radiation budget data and climate research, Rev. Geophys.,24, 439-468, 1986.

Key, J., Cloud cover analysis with Arctic Advanced Very High Resolution Radiometer data, 2, Classification with spectral and textural measures, J. Geophys. Res., 95, 7661-7675, 1990.

Key, J., and R. G. Barry, Cloud cover analysis with Arctic AVHRR data, 1, Cloud detection, J. Geophys. Res., 94, 18,521-18,535, 1989.

Kidder, S. Q., and H. T. Wu, Dramatic contrast between low clouds and snow cover in daytime 3.7- $\mu \mathrm{m}$ images, Mon. Weather Rev., 112, 2345-2346, 1984.

Kidwell, K. B., NOAA polar orbiter data users guide, Nath Environ. Satellite Data Inf. Serv., NOAA, Washington, D. C., 1985.

Kiehl, J. T., and V. Ramanathan, Comparison of cloud forcing derived from the Earth Radiation Budget Experiment with that simulated by the NCAR Community Climate Model, J. Geophys. Res., 95, 679-698, 1990.

Lauritson, L., G. J. Nelson, and F. W. Porto, Data extraction and calibration of TIROS-N/NOAA radiometers, NOAA Tech. Memo, NESS 107, Natl. Oceanic and Atmos. Admin., Washington D.C., 1979. Ramanathan, V., R. D. Cess, E. F. Harrison, P. Minnis, B. R. Barkstrom, E. Ahmad, and D. Hartmann, Cloud-radiative forcing and climate: Results from the Earth Radiation Budget Experiment, Science, 243, 57-63, 1989.

Raschke, E., T. H. Vonder Haar, M. Pasternak, and W. R. Bandeen, The radiation balance of the Earth-atmosphere system from Nimbus-3 radiation measurements, NASA Tech. Note TN D-7249, 73 pp. 1973. (Available as NTIS N7321702 from Natl. Tech. Inf. Serv., Springfield, Va.)

Raschke, E., Report of the International Satellite Cloud Climatology Project (ISCCP) workshop on cloud algorithms in polar regions, WCP-131, WMO/TD 170, World Clim. Res. Prog., World Meteorol. Org., Geneva, 1987.

Raschke, E., The International Satellite Cloud Climatology Project, ISCCP, and its European regional experiment ICE (International Cirrus Project), Atmos. Res., 21, 191-201, 1988.

Ruff, I., and A. Gruber, Multispectral identification of clouds and earth surfaces using AVHRR radiometric data, Prepr., 5th Conf. Atmos. Radiat., 475-478, Am. Meteorol. Soc., Baltimore, Md., 1983.

Sakellariou, N., and H. G. Leighton, Identification of cloud-free pixels in inhomogeneous surfaces from AVHRR radiances, $J$. Geophys. Res., 93, 5287-5293, 1988.

Saunders, R. W., and K. T. Kriebel, An improved method for detecting clear sky and cloudy radiances from AVHRR data, Int. J. Remote Sens., 9, 123-150, 1988.

Smith, G. L., R. N. Green, E. Raschke, L. M. Avis, J. T. Suttles, B. A. Wielicki, and R. Davies, Inversion methods for satellite studies of the Earth's radiation budget: Development of algorithms for the ERBE mission, Rev. Geophys., 24, 407-421, 1986.

Suttles, J. T., R. N. Green, P. Minnis, G. L. Smith, W. F. Staylor, B. A.Wielicki, I. J. Walker, D. F. Young, V. R. Taylor, and L. L. Stowe, Angular radiation models for Earth-atmosphere system, vol. 1, Shortwave radiation, NASA Ref. Publ. 1184, 114 pp., 1988.

Suttles, J. T., R. N. Green, P. Minnis, G. L. Smith, W. F. Staylor, B. A. Wielicki, I. J. Walker, D. F. Young, V. R. Taylor, and L. L. Stowe, Angular radiation models for Earth-atmosphere system, vol. 2, Longwave radiation, NASA Ref. Publ. 1184, 84 pp., 1989.

Taylor, V. R., and L. L. Stowe, Reflectance characteristics of uniform earth and cloud surfaces derived from Nimbus 7 ERB, J. Geophys. Res., 89, 4987-4996, 1984.

Twomey, S., and T. Cocks, Spectral reflectance of clouds in the nearinfrared: Comparisons of measurements and calculations, J. Meteorol. Soc. Jpn., 60, 583-592, 1982.

Vowinckel, E., and S. Orvig, The Climate of the North Polar basin, in World Survey of Climatology, vol. 14, Climates of the polar regions, 129-226, Elsevier, Amsterdam, 1970.

Welch, R. M., S. K. Cox, and J. M. Davis, Solar radiation and clouds, Meteorol. Monogr., 17 (39), 96 pp., 1980.

Wielicki, B. A, and R. N. Green, Cloud identification for ERBE radiative flux retrieval, J. Apph Meteorol. 28, 1133-1146, 1989.

Yamanouchi, T., K. Suzuki, and S. Kawaguchi, Detection of clouds in Antarctica from infrared multispectral data of AVHRR, J. Meteorol. Soc. Jpn., 65, 949-962. 1987.

H. G. Leighton and Z. Li, Department of Meteorology, McGill University, 805 Sherbrooke Street West, Montreal, Quebec, Canada H3A 2K6.
(Received October 29, 1990; revised February 12, 1991; accepted February 15, 1991.) 